\title{
Biting the dust with medical help: Should state law legitimize physician-assisted suicide?
}

\author{
Haider J. Warraich, MD, ${ }^{\mathrm{a}}$ Robert W. Sewell, MD, ${ }^{\mathrm{b}}$ and Robert M. Sade, MD
}

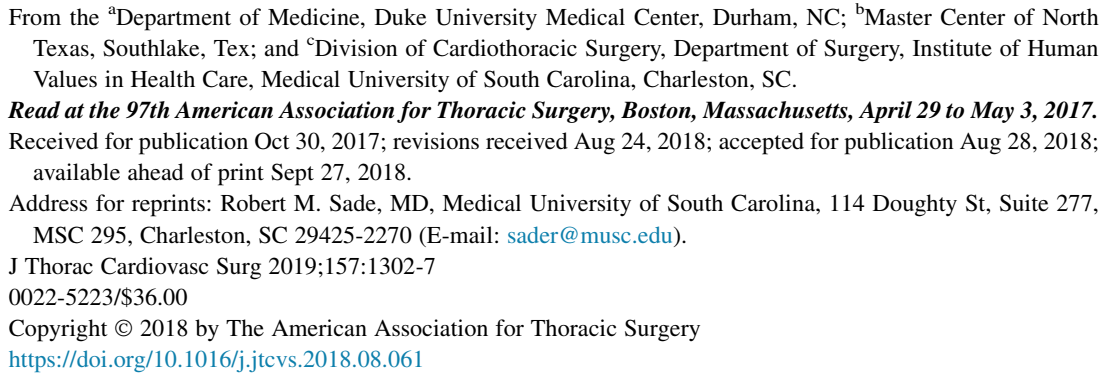

From the ${ }^{a}$ Department of Medicine, Duke University Medical Center, Durham, NC; ${ }^{b}$ Master Center of North Texas, Southlake, Tex; and ${ }^{c}$ Division of Cardiothoracic Surgery, Department of Surgery, Institute of Human Values in Health Care, Medical University of South Carolina, Charleston, SC.

Read at the 97th American Association for Thoracic Surgery, Boston, Massachusetts, April 29 to May 3, 2017. Received for publication Oct 30, 2017; revisions received Aug 24, 2018; accepted for publication Aug 28, 2018; available ahead of print Sept 27, 2018.

Address for reprints: Robert M. Sade, MD, Medical University of South Carolina, 114 Doughty St, Suite 277, MSC 295, Charleston, SC 29425-2270 (E-mail: sader@musc.edu).

J Thorac Cardiovasc Surg 2019;157:1302-7

$0022-5223 / \$ 36.00$

Copyright (c) 2018 by The American Association for Thoracic Surgery

https://doi.org/10.1016/j.jtcvs.2018.08.061

\section{INTRODUCTION}

\section{Robert M. Sade, MD}

I have firmly resolved to bite the dust, when my time comes, with a minimum of medical assistance, and up to then I will sin to my wicked heart's content. -Albert Einstein, $1913^{1}$

Should physicians actively help people to die when they have an incurable disease and want to end their lives? This question rested in the backwaters of public and professional interest until 1990, when Janet Adkins, a 57-year-old woman who had Alzheimer's disease, wanted to die; her wish was granted with the help of Jack Kevorkian, MD, a retired pathologist who made a career of assisting patients to commit suicide, starting with Adkins. ${ }^{2}$ Kevorkian ultimately helped 130 individuals to die. ${ }^{3}$ His bizarre ideas and peculiar behavior led to widespread condemnation of physician-assisted suicide (PAS), despite the positive views advocated by such highly respected clinicians and philosophers as Timothy Quill, MD, and Margaret Battin, PhD. Nearly every medical society that has addressed PAS has condemned the practice.

Physicians may be involved in the death of a patient in several different ways. Life support may be withdrawn from a critically ill patient in an intensive care unit at the request or agreement of the patient or a substitute decision maker; this is often referred to as passive euthanasia, but is legally and ethically acceptable because the patient is considered to have died of his disease. Active euthanasia is administering a substance or using other means to cause death; this act is illegal everywhere in the United States but may be acceptable in a few other countries, as noted below. PAS occurs when a physician supplies a patient with lethal means, usually a medication, and the patient causes his own death.

Public opinion has shifted regarding PAS. When Oregon adopted legislation permitting PAS in 1997, approval of the practice by the US public stood at $52 \%$ and, with some

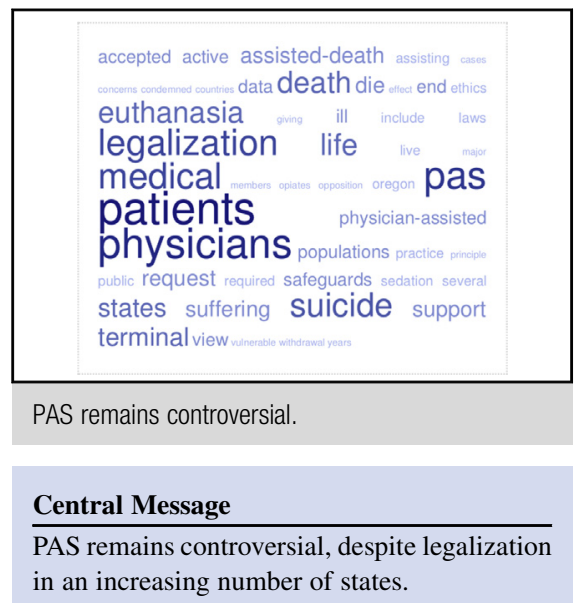

year-to-year variability, increased to $68 \%$ in $2015 .^{5}$ This popular view has been reflected in state laws: Since Oregon passed its statute, similar laws have been passed by Washington (2008), Vermont (2014), Colorado (2016), California (2016), and Hawaii (2018); it is legal also in the District of Columbia (2016) and in Montana (2009) by judicial findings. ${ }^{6}$ PAS is widely accepted in Europe; it is legal in The Netherlands, Belgium, Finland, Luxembourg, Switzerland, Germany, Albania, and Canada. ${ }^{7}$ Active euthanasia is legal under some circumstances in Belgium, Colombia, Luxembourg, and The Netherlands.

The current trend in state laws seems clear, but PAS remains illegal by statute in 36 states and by common law in 3 states. ${ }^{6}$ Legalization is under consideration, however, in at least a dozen other states. ${ }^{8}$ Legalization of PAS is a state-level issue that will be addressed in a political process, but it has substantial ethical implications for the practice of medicine as well. The question of legalization was debated at the 2017 American Association for Thoracic Surgery Annual Meeting, focused on the following vignette.

\section{THE CASE OF THE SURGEON-LAWMAKER'S DILEMMA}

Dr Charles Hobson is a retired cardiothoracic surgeon who sought and won a seat in his state legislature several years ago. He is known and respected for his thoughtfulness and integrity. Like most physicians, he has been opposed to PAS, mainly because he has believed that it is the role of physicians to heal and relieve suffering, not to cause death. However, he recognizes that there has been a gradual shift in the general population's attitude, moving toward support of 
PAS, and that several states, starting with Oregon 2 decades previously, have legalized PAS.

Dr Hobson chairs the legislature's Committee on Medical Affairs, and a bill to legalize PAS, with appropriate safeguards, has been presented to the committee for its consideration. After carefully reading the bill and consulting with his legislative colleagues, he must decide whether to move the bill forward to the whole legislature or quash it in committee. He asks 2 of his medical colleagues who have opposing views on this question to advise him on what they think he ought to do and why.

\section{PRO}

\section{Haider Warraich, MD}

Dr Hobson should support the bill and recommend legalization of physician-assisted death.

\section{Background}

Advances in medical therapies have changed death from a swift and singular event, to dying, a long drawn-out process. Even as life expectancy has increased, so too have the years people live with disability. Only 1 in 3 patients are able to pass away at home.

Therefore, even as we have witnessed the introduction of technology that allows us to live longer than ever before, so too have we seen the increase of the "right to die" movement, which seeks to allow patients to take control of how and when they would like to end their lives when faced with a terminal disease.

This movement is finding greater approval from the public and is winning at the ballot box: Many states have joined countries such as Canada and Switzerland in legalizing physician-assisted death. The laws passed in all these US states are almost identical: ${ }^{10}$ They allow competent adults to obtain an aid-in-dying prescription, after at least 2 separate requests to their physician and a consultant, who agree that the patient is unlikely to live more than 6 months and is free of any major psychiatric disorder, and other means to ease their symptoms have been exhausted.

\section{Opposition to Assisted Death}

Physicians' opposition to any form of assisted death started with Hippocrates, the Greek doctor whose oath is recited to this day by graduating medical students, who took a stand against what was routinely practiced in his time. What is less well remembered is that Hippocrates' oath also barred physicians from performing surgery, indicating perhaps how that document has aged. To this day, less than approximately half of physicians continue to oppose assisted suicide at all levels. The truth, though, is that although we physicians think that we have drawn a hard line in the sand, several of our accepted practices are even more active and oppressive of patients' autonomy than assisted death. ${ }^{11,12}$
Although many refer to this practice as suicide, what we need to understand is that these patients are not suicidal; it is not about whether they die or not but how they die; these patients have lived long lives and have had ups and downs; the vast majority of those who seek assisted death are elderly and highly educated; to call this suicide is to insult those suffering and those who have to make these difficult but well thought-out choices.

One of the cardinal features of modern death is that with the amount of artificial support at our disposal now, it is almost impossible for most patients to die unless physicians or patients' family members discontinue life support. Therefore, treatment withdrawal is now the most common way critically ill patients die in the hospital. Many times when patients are disconnected from mechanical ventilators, vasopressors, left ventricular assist devices, or permanent pacemakers, they can die almost instantaneously. Although withdrawal implies a passive act, in many cases the ending of life with termination of artificial support is decidedly active ${ }^{13}$ Unlike assisted death, which requires patients to be screened for depression, patients can ask for treatment withdrawal even if they have major depression or are suicidal. ${ }^{14}$ Furthermore, withdrawal decisions are usually made for patients who lack capacity and therefore have no voice in this decision. ${ }^{15}$

\section{Terminal Sedation and Double Effect}

In addition to treatment withdrawal, there is another principle, which at times appears very similar to assisted death. Many patients experience great pain or difficult breathing when the end is near. These patients almost universally receive opiate painkillers to help ease their symptoms, particularly if they are receiving palliative or hospice care. Even though these medications can slow down one's breathing to the point of complete stoppage, physicians and nurses are very comfortable giving these medications under the principle of the "double effect." ${ }^{16}$ The double effect gives us physicians the ability to prescribe medications that provide symptomatic relief even if they come with side effects that might hasten death.

Although the distinction between using opiates to ease suffering under the double-effect umbrella rather than to hasten death is clear in physicians' and nurses' minds for patients and family members, the lines between giving opiates for symptoms versus giving medications to shorten life are quite blurred. Furthermore, I always find it troubling to have a principle in which the sole arbiter is the clinician's intention. Who is to say what is one's intention when faced with a terminally ill patient struggling with dyspnea, for whom we prescribe escalating doses of opiates until they are comfortable.

In extreme cases, when even opiates are not enough to alleviate pain, patients are given sedation medications to ease their passage. The last time I administered what is 
called "terminal sedation," another accepted strategy, was in a patient with abdominal cancer with intestinal perforation for whom surgery was not an option. ${ }^{17}$ The patient, who had been writhing uncontrollably in pain, was finally comfortable. Yet terminal sedation, necessary as it was, can be considered closer to active euthanasia than even assisted death given that it is actively ordered by the physician and is usually given in patients who lack decision-making capacity.

\section{Slippery Slopes, Safeguards, and Self-Determination}

While how people die has changed, the arguments made against assisted death have not. We are warned of a slippery slope, implying that legalization of assisted death would eventually lead to eugenic sterilization reminiscent of Nazi Germany, but no such drift has been observed in any of the countries where it has been legalized. ${ }^{18}$ We are cautioned that legalization would put vulnerable populations such as the uninsured and the disabled at risk. However, years of data from Oregon demonstrate that the vast majority of patients in Oregon who opt for it are white, affluent, insured, and highly educated. ${ }^{19} \mathrm{We}$ are told that it will allow people to ignore providing high-quality palliative care to patients, but the data suggest only the opposite: A strong argument for legalization of assisted death is that it sensitizes physicians even more so than before about ensuring their patients' comfort when they face terminal illnesses. ${ }^{20}$ And last, we are counseled that physicians should do no harm, but medical harm is already one of the leading causes of death, and to me, preventing patients from achieving an end on their terms is also a form of medical harm. $^{21}$

The end of life has changed dramatically over the past few decades, and so must we.

\section{CON}

\section{Robert Sewell, MD}

Dr Hobson should reject the legalization of PAS.

\section{Background}

The founders of our country identified their core values in the Declaration of Independence by including the words, "We hold these truths to be self-evident, that all men are created equal, that they are endowed by their Creator with certain unalienable Rights, that among these are Life, Liberty and the pursuit of Happiness." 22 Historically, virtually every civilization has included a fundamental respect for and protection of human life, placing it at or near the top of their list of core values. While the question when life begins and when it ends is widely debated, the prohibition on the willful taking of an innocent life, even one's own life, is perhaps the most universal of all principles governing human societies.
The sanctity of life is also at the heart of all the world's major religions, and suicide is specifically condemned by each of them on moral grounds. For most of recorded history, the taking of one's own life has been considered a crime, usually punished by confiscation of the decedent's property. ${ }^{23}$ In modern times, suicide has been decriminalized, largely because punishment of the surviving spouse and children by confiscating their inheritance has been deemed to be cruel and unusual punishment. Even so, suicide remains widely condemned today. ${ }^{24}$

Although suicide is no longer considered illegal, the same cannot be said for assisting suicide. In most states, it is still a crime to assist a person in the voluntary taking of his own life. Assisting suicide has been legalized in several states recently, but only when carried out by a physician: Oregon, Washington, Vermont, Montana, California, Colorado, and the District of Columbia. ${ }^{25}$ In my view, these states have set upon a dangerous course.

\section{Reasons to Oppose Physician-Assisted Suicide}

The Greek philosopher Plato taught that suicide was disgraceful, but proposed certain circumstances when it was acceptable, including, "When self-killing is compelled by extreme and unavoidable personal misfortune." ${ }^{26}$ Hippocrates offered a different view, holding that life was a sacred gift from the gods and was to be cherished and protected. His oath required physicians to agree: "I will neither give a deadly drug to anybody who asked for it, nor will I make a suggestion to this effect." ${ }^{27}$ This basic ethical principle has guided physicians for 2500 years, and the suggestion that a physician should actively participate in the willful termination of any human life is antithetical to those time-honored ethics.

Several practical considerations support opposition to PAS, including threats to vulnerable populations, failure of legal safeguards, and undermining the physicianpatient relationship and the culture of medicine.

\section{Slippery Slope}

Jackson and Keown ${ }^{28}$ point out the logic of the potential progression from assisted suicide to euthanasia.

If compassion justifies us in getting a lethal prescription to a terminally ill patient on request to end their suffering, it would equally justify us in giving them a lethal injection, particularly if they were physically unable to commit suicide. It would also justify us in getting a lethal injection to a terminally ill patient who was incapable of making a request. ${ }^{28}$

In fact, 5 countries now permit euthanasia on those grounds: The Netherlands, Belgium, Luxembourg, Japan, and Colombia. ${ }^{29}$ It seems inevitable that euthanasia will be legalized in states that already permit PAS because it is 
illogical (not to mention lacking in compassion) not to include it. Unfortunately, those who are most likely to be the objects of PAS or euthanasia are vulnerable or marginalized populations, such as the elderly, the poor, or those without access to good medical care.

\section{Failure of Legal Safeguards}

There are many reasons to be concerned about the inadequacy of safeguards against abuses of PAS. Those safeguards have been described as "largely illusory" by a leading California law professor. ${ }^{30}$ Witnesses to a request for PAS may include a family member who has an incentive, such as financial gain, for the patient to die; there are virtually no requirements for ensuring that the patient's request is entirely voluntary and free from coercion or undue pressure. Physicians are immunized against making mistakes or bad judgments as long as they act in "good faith," a very loose and subjective criterion, so in essence, family members have no recourse if they learn that a physician has been grossly negligent, perhaps by misdiagnosing a terminal condition or incorrectly assessing the patient as being competent. ${ }^{31}$

Such concerns have proved to be valid, based on data from other countries. Guidelines for the conduct of PAS and euthanasia in The Netherlands, such as an explicit request for death from the patient, verification of a request by 2 physicians, and required reporting, have been extensively violated with virtual impunity. ${ }^{32}$ A study in 2010 reported that one-third of PAS and euthanasia deaths in Belgium occurred without a request by the patient. ${ }^{33}$ (We note that although the required explicit request from the patient was not present, consent was usually obtained from a family member.) Regarding such violations of guidelines, a leading US bioethicist wrote, "Indeed, the persistence of abuse and the violation of safeguards, despite publicity and condemnation, suggest that the feared consequences of legalization are exactly its inherent consequences." ${ }^{34}$

Concern that assistance in dying will be a particular threat to vulnerable populations, such as children and the disabled, is supported by the fact that PAS and euthanasia in Belgium and The Netherlands have gradually been permitted for infants and children, as well as individuals who are not dying but suffer from a variety of disabilities. ${ }^{35-37}$

\section{Undermining the Physician-Patient Relationship and the Culture of Medicine}

The fundamental commitment of physicians as members of the medical profession is to heal illness and relieve suffering. PAS is antithetical to the very nature of what it means to be a physician. A former chair of the President's Council on Bioethics put it this way:

The legalization of PAS will pervert the medical profession by transforming the healer of human beings into a technical dispenser of death. For more than 2 millennia, the medical ethic, mindful that power to cure is also power to kill, has held as an inviolable rule, "Doctors must not kill." 38

The reasoning underlying that statement led the American Medical Association to condemn PAS: "Physician-assisted suicide is fundamentally incompatible with the physician's role as healer, would be difficult or impossible to control, and would pose serious societal risks." ${ }^{39}$ Dozens of other medical associations and groups representing vulnerable populations have similarly gone on record as opposing PAS and euthanasia.

The foundation of the relationship between physicians and their patients, the sine qua non of the healing process, is the patient's trust in the physician. If the physician is not trustworthy, patients will not do what the physician advises and cannot benefit from the physician's art and science. Trust that the physician's role is solely to heal, not to harm, is precisely the aspect of medical care that PAS undermines. ${ }^{40}$ As a physician, Dr Hobson should understand this basic principle of medicine and therefore confidently reject the legislation he has been asked to consider. Physicians do not kill, and PAS should not be legalized.

\section{CONCLUDING REMARKS}

Robert M. Sade, MD

Dr Warraich supports PAS, arguing that public approval is high and presenting evidence that concerns about bias against poor and less well-educated populations are unwarranted. He points out that physicians already cause death in other ways that are ethically acceptable, such as withdrawal of life support, sedation with opiates and sedatives that accelerate dying, and terminal sedation for uncontrollable suffering. PAS is one more way we can help terminally ill patients to have a peaceful, dignified death, in his view.

Dr Sewell cites the historical foundations of medical ethics, which advocate for healing and alleviating suffering and against causing death. He also cites evidence that safeguards against abuses of PAS have failed in the past, resulting in prohibited euthanasia, often without the patient's consent and violations of other safeguards. He supports medical societies' opposition to PAS on grounds of perversion of professionalism and inevitable undermining of patients' trust in their physicians and in the medical profession.

As in the general population, support for PAS appears to be growing among physicians. A repeated survey of physicians by Medscape over the past several years has shown increasingly positive views by physicians. Approval of PAS increased from $46 \%$ to $57 \%$ between 2010 and 2016. Perhaps more significantly, the disapproval rates decreased from $41 \%$ to $29 \%$ in the same years. ${ }^{41}$ These surveys are conducted online, include only Medscape readers, and in 2016 had only 7500 respondents, so the data's generalizability is questionable. Yet, these are the only linear 
time-related data we have regarding the views of physicians, to my knowledge.

One of the serious concerns about legalization of PAS is the lack of reliable data to assess the frequency of PAS and euthanasia and of guidelines violations. Reporting cases is required by the US states in which PAS is legal, yet the number of unreported instances is unknown. Oregon and Washington have the longest-standing permissive laws, yet high-quality data on the prevalence of euthanasia and of continuous deep sedation are not available. ${ }^{42}$ These states have failed to track information about complications and abuses. ${ }^{43}$ Data from Switzerland, where PAS is legal but euthanasia is not, indicate that in 2013, death was caused by euthanasia in 10 cases and life was ended without the required patient's explicit request in 25 cases. ${ }^{44}$ Comparable data are unfortunately not available in the United States.

PAS is clearly becoming more widely accepted in the United States by both the medical and lay populations. There are reasons to be concerned about this trend; better tracking of the prevalence and results of such policies is sorely needed. The American people deserve greater transparency about the results of these policies to enlighten and enrich public debate about the potential benefits and possible harms.

\section{Conflict of Interest Statement}

R.M.S.'s role in this publication was supported by the South Carolina Clinical and Translational Research Institute, Medical University of South Carolina's Clinical and Translational Science Award Number UL1TR001450. The contents are solely the responsibility of the authors and do not necessarily represent the official views of the National Center for Advancing Translational Science of the National Institutes of Health. All other authors have nothing to disclose with regard to commercial support.

\section{References}

1. Calaprice A. The Ultimate Quotable Einstein. Princeton, NJ: Princeton University Press; 2011:91.

2. Editorial. Dying, Dr. Kevorkian's way. New York Times. June 7, 1990. Available at: http://www.nytimes.com/1990/06/07/opinion/dying-dr-kevorkian-s-way.html. Accessed June 13, 2017.

3. Kraft S. Jacob "Jack" Kevorkian dies; death with dignity proponent remembered. Medical News Today. Available at: http://www.medicalnewstoday.com/ articles/227470.php. Accessed June 13, 2017.

4. Quill T, Battin M. Physician-Assisted Dying: The Case for Palliative Care and Patient Choice. Baltimore, MD: The Johns Hopkins University Press; 2004.

5. Dugan A. In U.S., support up for doctor-assisted suicide. Gallup Poll Social Series. Available at: http://www.gallup.com/poll/183425/support-doctor-assistedsuicide.aspx. Accessed June 13, 2017.

6. State-by-state guide to physician-assisted suicide. February 21, 2017. Available at: http://euthanasia.procon.org/view.resource.php?resourceID $=000132$. Accessed June 13, 2017.

7. Euthanasia \& physician-assisted suicide (PAS) around the world: legal status in 28 countries from Australia to Uruguay. July 20, 2016. Available at: http:// euthanasia.procon.org/view.resource.php?resourceID $=000136$. Accessed June 13, 2017.

8. Monir M. Half the states look at right-to-die legislation. USA Today. April 16, 2015.
9. Warraich HJ, Hernandez AF, Allen LA. How medicine has changed the end of life for patients with cardiovascular disease. J Am Coll Cardiol. 2017;70:1276-89.

10. McGreevy P. Guidelines issued for California's assisted suicide law. Los Angeles Times. January 19, 2017. Available at: http://www.latimes.com/politics/la-polsac-guidelines-california-assisted-suicide-law-20160120-story.html. Accessed June 13, 2017.

11. Rietjens JAC, van Delden JJM, van der Heide A. Terminal sedation and euthanasia: a comparison of clinical practices. Arch Intern Med. 2006;166: 749-53.

12. Battin MP. Terminal sedation: pulling the sheet over our eyes. Hastings Cent Rep. 2008;38:27-30.

13. Orentlicher $\mathrm{D}$. The alleged distinction between euthanasia and the withdrawal of life-sustaining treatment: conceptually incoherent and impossible to maintain. Univ Ill Law Rev. 1998;1998:837-59.

14. Sontheimer D. Suicide by advance directive? J Med Ethics. 2008;34:e4.

15. Prendergast TJ, Claessens MT, Luce JM. A national survey of end-of-life care for critically ill patients. Am J Respir Crit Care Med. 1998;158:1163-7.

16. Mangan JT. An historical analysis of the principle of double effect. Available at: https://philpapers.org/archive/manaha-2. Accessed June 13, 2017.

17. Orentlicher D. The Supreme Court and terminal sedation: rejecting assisted suicide, embracing euthanasia. Hastings Constit Law Q. 1997;24:947-68.

18. Emanuel EJ, Onwuteaka-Philipsen BD, Urwin JW, Cohen J. Attitudes and practices of euthanasia and physician-assisted suicide in the United States, Canada, and Europe. JAMA. 2016;316:79-90.

19. Oregon Public Health Division. Death with Dignity Annual Report. February 21, 2017. Available at: http://public.health.oregon.gov/ProviderPartnerResources/ EvaluationResearch/DeathwithDignityAct/Documents/year16.pdf. Accessed June 13, 2017.

20. Marquet RL, Bartelds A, Visser GJ, Spreeuwenberg P, Peters L. Twenty-five years of requests for euthanasia and physician assisted suicide in Dutch general practice: trend analysis. BMJ. 2003;327:201-2.

21. Makary MA, Daniel M. Medical error-the third leading cause of death in the US. BMJ. 2016;353:i2139.

22. The Declaration of Independence. Available at: http://www.ushistory.org/ declaration/document/. Accessed June 2, 2017.

23. Bracton H (1968). Cited in Gorsuch N. In: Thorne Samuel E, ed. On the law and customs of England 424. The Future of Assisted Suicide and Euthanasia, 238. Princeton, NJ: Princeton University Press; 2009. Ref 55.

24. Finnis J. Moral Absolutes: Tradition, Revision and Truth. Washington, DC: The Catholic University of America Press; 1991:1-30.

25. State-by-State Guide to Physician-Assisted Suicide. Available at: http:// euthanasia.procon.org/view.resource.php?resourceID $=000132$. Accessed June 2, 2017.

26. Plato. Laws IX 873 c-d. In: The Dialogues of Plato, Vol. 2, Jowett B. Translation. New York: Random House; 1937:618.

27. Hippocrates. Hippocratic Oath. Johns Hopkins Sheridan Libraries. Available at: http://guides.library.jhu.edu/c.php?g=202502\&p=1335752. Accessed June 2, 2017.

28. Jackson E, Keown J. Debating Euthanasia. Oxford: Hart Publishing; 2011:102.

29. Euthanasia regulations around the world. Available at: https:/ethicslab. georgetown.edu/euthanasia-map/text.html. Accessed June 2, 2017.

30. Capron AM. Legalizing physician-aided death. Camb Q Healthc Ethics. 1996;5: $10-23$.

31. Gorsuch NM. The Future of Assisted Suicide and Euthanasia. Princeton, NJ: Princeton University Press; 2006:119.

32. Keown J. Euthanasia in The Netherlands: sliding down the slippery slope? Notre Dame J Law Ethics Public Policy. 1995;9:407-48. Available at: http:// scholarship.law.nd.edu/cgi/viewcontent.cgi?article $=1427 \&$ context=ndjlepp. Accessed June 2, 2017.

33. Chambaere K, Bilsen J, Cohen J, Onwuteaka-Philipsen BD, Mortier F, Deliens L. Physician-assisted deaths under the euthanasia law in Belgium: a populationbased survey. CMAJ. 2010;182:895-901. Available at: http://www.cmaj.ca/ content/182/9/895.full. Accessed June 2, 2017.

34. Emanuel EJ. Whose right to die? The Atlantic. March 1, 1997. Available at: http://www.theatlantic.com/magazine/archive/1997/03/whose-right-to-die/304641/. Accessed June 2, 2017.

35. Verhagen E, Sauer PJJ. The Groningen protocol—euthanasia in severely ill newborns. N Engl J Med. 2005;352:960-1.

36. Blyth B. Federal parliament passes euthanasia law for minors. Flanders Today. February 14, 2014. Available at: http://www.flanderstoday.eu/politics/federalparliament-passes-euthanasia-law-minors. Accessed June 2, 2017. 
37. Reid S. The country where death is now just a lifestyle choice: a mum with ringing ears. Babies whose parents don't want them to suffer. They've all been allowed to die by assisted suicide in Holland. Daily Mail, January 1, 2015. Available at: http://www.dailymail.co.uk/news/article-2893778/As-debateassisted-suicide-dispatch-Holland-thousands-choose-die-year.html. Accessed June 2, 2017

38. Kass LR. Dehumanization triumphant. First things. August, 1996. Available at: https://www.firstthings.com/article/1996/08/dehumanization-triumphant. Accessed June 2, 2017.

39. Council on Ethical and Judicial Affairs. Physician-assisted suicide. Opinion 2.211. In: Code of Medical Ethics of the American Medical Association, Ed. 2014-2015. Chicago: American Medical Association; 2014:119-128.
40. Sade RM. Let common law continue to control assisted suicide. The Greenville News. Greenville, SC. July 13, 1997.

41. Kane L. Medscape Ethics Report 2014: Life, death, and pain. Available at: http:// www.medscape.com/features/slideshow/ethics2016-part2\#page=2. Accessed June 14, 2017.

42. Ganzini L, Back AL. The challenge of new legislation on physician-assisted death. JAMA Intern Med. 2016;176:427-8.

43. Stevens KR, Toffler WL. Euthanasia and physician-assisted suicide. JAMA 2016;316:1599.

44. Bosshart G, Zellweger U, Bopp M, Schmid M, Hurst SA, Puhan MA, et al. Medical end-of-life practices in Switzerland: a comparison of 2001 and 2013. JAMA Intern Med. 2016;176:555-6. 